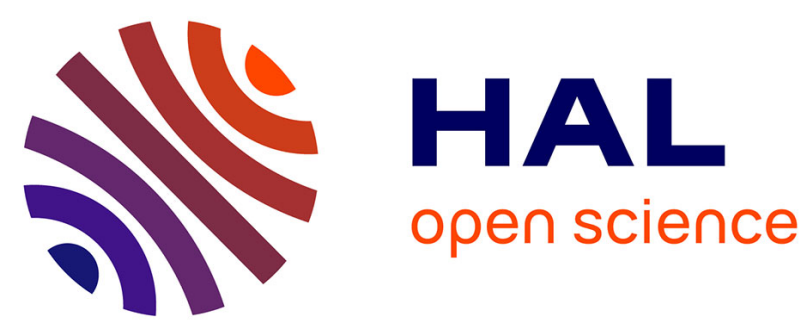

\title{
Assessing the accuracy and precision of manual registration of both femur and tibia using EOS imaging system with multiple views
}

Karine Langlois, Hélène Pillet, François Lavaste, Goulven Rochcongar, Philippe Rouch, Patricia Thoreux, Wafa Skalli

\section{To cite this version:}

Karine Langlois, Hélène Pillet, François Lavaste, Goulven Rochcongar, Philippe Rouch, et al.. Assessing the accuracy and precision of manual registration of both femur and tibia using EOS imaging system with multiple views. Computer Methods in Biomechanics and Biomedical Engineering, 2015, 18, pp.1972-1973. 10.1080/10255842.2015.1072416 . hal-02568806

\section{HAL Id: hal-02568806 https://hal.science/hal-02568806}

Submitted on 10 May 2020

HAL is a multi-disciplinary open access archive for the deposit and dissemination of scientific research documents, whether they are published or not. The documents may come from teaching and research institutions in France or abroad, or from public or private research centers.
L'archive ouverte pluridisciplinaire HAL, est destinée au dépôt et à la diffusion de documents scientifiques de niveau recherche, publiés ou non, émanant des établissements d'enseignement et de recherche français ou étrangers, des laboratoires publics ou privés. 


\title{
Assessing the accuracy and precision of manual registration of both femur and tibia using EOS imaging system with multiple views
}

\author{
K. Langlois ${ }^{\mathrm{a}}$, H. Pillet ${ }^{\mathrm{a}}$, F. Lavaste ${ }^{\mathrm{a}}$, G. Rochcongar ${ }^{\mathrm{b}}$, P. Rouch ${ }^{\mathrm{a}}$, P. Thoreux ${ }^{\mathrm{a}, \mathrm{c}}$ and W. Skalli ${ }^{\mathrm{a}}$

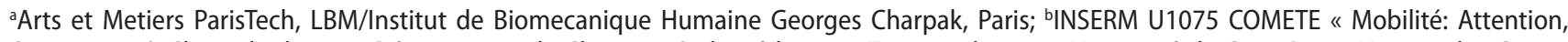 \\ Orientation \& Chronobiologie », Département de Chirurgie Orthopédique et Traumatologique, Université de Caen Basse-Normandie, Centre \\ Hospitalier Universitaire de Caen, France; ‘Service de Chirurgie Orthopédique Hôpital Avicenne, Université Paris XIII, Bobigny
}

KEYWORDS Biplanar low dose; knee flexion; registering; lower limb

\section{Introduction}

The EOS imaging system produces two simultaneous $\mathrm{X}$-rays of a subject. Both views are used for the generation of a subject-specific 3D skeletal model. This model then allows to obtain quantitative parameters concerning the morphology and the positioning of bones. Furthermore, thanks to the low dose of the EOS imaging, it is possible to take several stereoradiographies of the same subjects in order to study different positions of the femoro-patellar joint (Dagneaux et al. 2014) or to analyze different positions of the subjects. Also, it can be a way to compare tibia and femur relative positions without and with an orthotic device such as a brace for example. For that, the $3 \mathrm{D}$ model, obtained from the reference standing position, is registered across the different pairs of X-rays for the other positions. The goals of this study are $1 /$ to evaluate the reproducibility of the registration of both in vitro and in vivo and $2 /$ to assess the accuracy of this manual method using in vitro data.

\section{Methods}

\subsection{Protocol}

Twelve lower extremities (femur and tibia) were used: six cadaveric lower limbs of six healthy subjects who signed an approved consent form before participating in this study. In vitro analysis: for each cadaveric lower limb, an experimental device allows to capture three pairs of views of the specimen, the femur being fixed to the device $\left(0^{\circ}, 20^{\circ}\right.$, and $40^{\circ}$ of knee flexion) (Rochcongar et al. 2014). In addition, clusters of markers were rigidly fixed in each bone to get reference value of the bone position in different knee flexion positions. For each healthy subject, the protocol consisted in performing four pairs of views in standing $\left(0^{\circ}\right)$ and knee flexion positions $\left(20^{\circ}, 40^{\circ}\right.$, and $\left.90^{\circ}\right)$. Here, femur and tibia were mobile. For both in vitro and in vivo analyses, three qualified operators performed 1 / the lower limb reconstruction using the standing position pair of views and 2/ the manual registration of the $3 \mathrm{D}$ skeletal models of the femur and the tibia on each pair of views for each position of knee flexion (Figure 1). Each operator performed three repetitions of this process for each lower limb.

\subsection{Parameters computation process}

From femur and tibia 3D models, anatomical frames were computed according to the definition proposed by Schlaterer et al. (2009) for each knee position and each repetition. Then, the position and the orientation of each bone relatively to the EOS coordinate system was assessed for each knee flexion position and expressed by six parameters: anteroposterior $(x)$, longitudinal $(y)$, and mediolateral $(z)$ translations $\left(T_{x}, T_{y}\right.$, and $\left.T_{z}\right)$ and rotations $\left(R_{x}, R_{y}\right.$, and $\left.R_{z}\right)$. The relative position of the tibia and the femur was also calculated.

\subsection{Data analysis}

The precision of the method was assessed according to NF ISO-5725-1, 1994, and NF ISO-5725-2, 1994. Inter-operator reproducibility and intra-operator repeatability of femur and tibia regarding the six parameters were determined to estimate the uncertainty of the registering method concerning femur and tibia. The uncertainty of manual positioning was estimated by the IC 95\% for both cadaveric and healthy groups for each position and each parameter. IC $95 \%$ reliability was considered as $2 \sigma R$. Furthermore, from in vitro data, an average position of each bone was assessed from the repetitions of the three operators and used to evaluate the accuracy of the method by comparing the resulting variation of positions between each pair of views and the true value given by the clusters embedded in the bones and visibles on the radios.

\section{Results and discussion}

Confidence intervals at $95 \%$ for the bone pose parameters of both femur and tibia are presented in Table 1. Results are 
Table 1. IC 95\% of the interoperator reliability for each position and orientation parameter.

\begin{tabular}{|c|c|c|c|c|c|c|c|c|}
\hline In vivo & Parameter & $20^{\circ}$ & $40^{\circ}$ & $90^{\circ}$ & In vitro & Parameter & $20^{\circ}$ & $40^{\circ}$ \\
\hline IC 95\% reliability & $T_{x}(\mathrm{~mm})$ & 1.1 & 1.1 & 1.1 & & & & \\
\hline Femur healthy & $T^{x}(\mathrm{~mm})$ & 1.0 & 1.2 & 1.2 & & & & \\
\hline \multirow{4}{*}{ subjects } & $T^{y}(\mathrm{~mm})$ & 1.3 & 1.4 & 1.8 & & & & \\
\hline & ${ }^{2} R_{y}\left({ }^{\circ}\right)$ & 0.7 & 0.9 & 1.4 & & & & \\
\hline & $R\left(0^{\circ}\right)$ & 3.7 & 2.9 & 3.2 & & & & \\
\hline & $R_{z}^{y}\left({ }^{\circ}\right)$ & 0.4 & 0.5 & 0.6 & & & & \\
\hline IC 95\% reliability & $T_{x}(\mathrm{~mm})$ & 1.2 & 1.6 & 1.5 & IC 95\% reliability tibia & $T_{x}(\mathrm{~mm})$ & 1.6 & 2 \\
\hline \multirow[t]{5}{*}{ tibia healthy subjects } & $T^{x}(\mathrm{~mm})$ & 1.5 & 1.5 & 1.9 & cadaveric & $T^{x}(\mathrm{~mm})$ & 1.6 & 2 \\
\hline & $T_{3}^{y}(\mathrm{~mm})$ & 1.7 & 2.2 & 2.7 & & $T_{2}^{y}(\mathrm{~mm})$ & 1.6 & 2 \\
\hline & $R\left(0^{\circ}\right)$ & 0.9 & 1.9 & 2.8 & & $R\left(0^{\circ}\right)$ & 1.6 & 3.2 \\
\hline & $R^{x}\left({ }^{\circ}\right)$ & 5.1 & 4.4 & 4.8 & & $R^{x}\left({ }^{\circ}\right)$ & 5.4 & 5.4 \\
\hline & $R_{z}\left({ }^{\circ}\right)$ & 0.4 & 0.4 & 0.3 & & $R_{z}\left({ }^{\circ}\right)$ & 0.4 & 0.6 \\
\hline IC 95\% reliability & $\mathrm{Tx}(\mathrm{mm})$ & 1.8 & 2.3 & 2.4 & IC 95\% reliability knee & $T^{2}(\mathrm{~mm})$ & 1.6 & 2 \\
\hline knee healthy & Ty $(\mathrm{mm})$ & 2.0 & 2.3 & 3.3 & cadaveric & $T_{v}^{x}(\mathrm{~mm})$ & 1.8 & 2 \\
\hline \multirow[t]{4}{*}{ subjects } & $\mathrm{Tz}(\mathrm{mm})$ & 2.4 & 2.9 & 3.6 & & $T_{z}(\mathrm{~mm})$ & 1.8 & 2.4 \\
\hline & $\operatorname{Rx}\left(0^{\circ}\right)$ & 1.9 & 2.8 & 4.2 & & $R_{y}\left({ }^{\circ}\right)$ & 1.8 & 3 \\
\hline & $\operatorname{Ry}\left({ }^{\circ}\right)$ & 5.5 & 4.8 & 3.6 & & $R_{y}\left({ }^{\circ}\right)$ & 5.6 & 5.6 \\
\hline & $\operatorname{Rz}\left({ }^{\circ}\right)$ & 0.6 & 0.5 & 0.7 & & $R_{z}\left({ }^{\circ}\right)$ & 0.4 & 0.6 \\
\hline
\end{tabular}

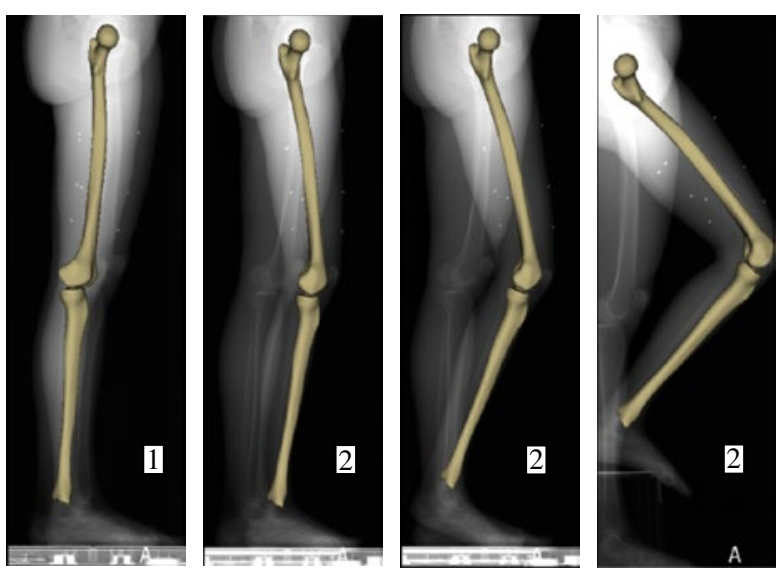

Figure 1. Illustration of the process on the sagittal view: $1 /$ the lower limb reconstruction on the standing position view and 2/ the manual registration of the 3D skeletal models of the femur and the tibia on each position of knee flexion.

shown for each knee flexion and for each translation and rotation parameter.

No results are presented for the femur bone in vitro conditions since the bone was fixed on the experimental device.

The precision of the femur registration was better than the one of the tibia. The precision of the registration was less than $0.6^{\circ}$ along the mediolateral $(z)$ axis and $2.8^{\circ}$ along the anteroposterior $(x)$ axis for both femur and tibia.

In this study, maximum degrees of uncertainty for the knee (ranging from $3.6^{\circ}$ to $5.5^{\circ}$ according to positions of knee flexion) were found along the longitudinal axis $(y)$. These results are mainly related to the tibia registration error and are in favor of a stereoradiographic protocol in which the tibia would remain fixed throughout the different views. In comparison, Chaibi et al. (2012) reported an uncertainty inferior to $2.7^{\circ}$ for reconstruction parameters of both femur and tibia except for torsion parameters $\left(<5^{\circ}\right)$ which is consistent with our results.

Regarding the accuracy of tibia registration (in vitro data), for the $20^{\circ}$ knee flexion position, the deviations between the values from the registration of bones and the true values for the $R_{x}, R_{y}$, and $R_{z}$ were, respectively, $-0.7^{\circ},-0.8^{\circ}$, and $0^{\circ}$. For the translation parameters $T_{x}, T_{y}$, and $T_{z}$, the deviations were, respectively, $-0.2,0.6$, and $0.2 \mathrm{~mm}$. In vitro, these values demonstrated high accuracy for sagittal and coronal planes.

Accuracy and precision of this current method can be compared to fluoroscopic approach, which also uses the registration of the $3 \mathrm{D}$ model on a $2 \mathrm{D}$ view. Regarding out of plane registration in these studies, our results are in agreement with the parameters $R_{x}$ and $T_{z}$. Registration from EOS is easier for $R_{z}$.

\section{Conclusions}

The purpose of this study was to assess the manual registration of 3D skeletal models of the femur and the tibia for different positions of knee flexion. This method allows to obtain body segments displacements which could improve measurements of knee kinematics or evaluate the effect of an orthotic device. Results of this study may be considered in research for protocols including several views of the lower limb.

\section{References}

Chaibi Y, Cresson T, Aubert B, Hausselle J, Neyret P, Hauger O, de Guise JA, Skalli W. 2012. Fast 3D reconstruction of the lower limb using a parametric model and statistical inferences and clinical measurements calculation from biplanar X-rays. Comput Biomech Biomed Eng. 15:457-466.

Dagneaux L, Thoreux P, Cyteval C, Canovas F, Skalli W. 2014. Analyse $3 \mathrm{D}$ de la cinématique séquentielle des troubles fémoro-patellaires à partir de radiographies biplanaires [3D pseudo-kinematic analysis of patellofemoral diseases by using biplanar radiographs]. Rev Chir Orthop. 100:S280.

Rochcongar G, Pillet H, Bergamini E, Thoreux P, Rouch P. 2014. Assessment of kinematics, anatomy and variation of ligaments length during a passive knee flexion. Rev Chir Orthop. 100:e38-e39.

Schlatterer B, Suedhoff I, Bonnet X, Catonne Y, Maestro M, Skalli W. 2009. Skeletal landmarks for TKR implantations: evaluation of their accuracy using EOS imaging acquisition system. Orthop Traumatol. 95:2-11. 